\title{
ANALISA BUSINESS PROCESS REENGINEERING DALAM PENGEMBANGAN SISTEM DISTRIBUSI PRODUK LENSA MATA PT. GALERI MATA INDONESIA BERBASIS MOBILE APPLICATION
}

\author{
Riri Fajriah ${ }^{1}$, Syukri Nazar ${ }^{2}$ \\ 1,2 Program Studi Sistem Informasi Fakultas Ilmu Komputer Universitas Mercu Buana \\ Jalan Meruya Selatan No. 1 Kembangan Jakarta Barat \\ ${ }^{1}$ riri.fajriah@mercubuana.ac.ids, ${ }^{2}$ syukri.nazar@mercubuana.ac.id
}

\begin{abstract}
Abstrak-Business process reengineering adalah salah satu cara yang dapat dilakukan oleh perusahaan untuk memperbaiki kinerja operasional bisnis. Permasalahan yang sering dihadapi oleh perusahaan distribusi adalah bagaimana menjaga komitmen yang baik kepada pelanggan dalam hal pengantaran produk yang dapat diterima tepat waktu dan dalam kondisi yang baik. Hal ini pun yang menjadi perhatian pada PT Galeri Mata Indonesia sebagai salah satu perusahaan yang bergerak di bidang distribusi produk lensa mata. Oleh karena itu perusahaan berencana untuk melakukan tinjauan evaluasi bisnis proses yang berjalan saat ini dengan mengimplementasikan metode analisa value chain dan critical success factor (CSF). Adapun konsep business process reengineering yang akan dilakukan bertujuan untuk memberikan hasil analisa perbaikan proses bisnis dan strategi perencanaan rancangan pengembangan sistem distribusi yang akan dilakukan oleh PT Galeri Mata Indonesia berbasis mobile application. Sehingga pelayanan distribusi lensa mata kepada pelanggan dapat mencapai service level agreement (SLA) yang baik, memuaskan serta meningkatkan keuntungan perusahaan.
\end{abstract}

Kata Kunci-Business Process Reengineering, Value Chain, CSF, SLA, Distribusi, Mobile Application

Abstract- Business process reengineering is one-way companies can do to improve business operational performance. The problem that is often faced by distribution companies is how to maintain good commitment shown to customers in terms of product delivery that can be received on time and in good condition. This also concerns PT Galeri Mata Indonesia as one of the companies engaged in the distribution of eye products. By because it company is planning to review the Business Process Evaluation that is currently running now by implementing the value chain analysis method and critical success factors (CSF). While the concept of business process reengineering will be carried out to provide results of business process improvement analysis and distribution system development planning that will be carried out by PT Galeri Mata Indonesia based on mobile applications. So that the eyepiece distribution service is not shown to customers can achieve a good service level agreement (SLA), Satisfying and increasing corporate profits.

Keywords - Business Process Reengineering, Value Chain, CSF, SLA, Distribution, Mobile Application

\section{PENDAHULUAN}

Business Process Reengineering (BPR) adalah salah satu strategi yang dapat diimplementasikan oleh organisasi bisnis dalam upaya meningkatkan pelayanan kepada pelanggan. Dalam konsep Business Process Reengineering (BPR), organisasi bisnis akan membentuk konsep proses bisnis yang dirubah untuk meningkatkan jasa kepada pelanggan, memotong biaya operasional dan menjadi kompetitor kelas dunia [1].

Perubahan proses bisnis (Business Process Reengineering) dengan penerapan model e-Commerce menunjukkan perubahan usaha kearah yang lebih maju disamping tujuan utamanya adalah untuk efisiensi biaya dan waktu serta tentunya dalam peningkatan laba atau keuntungan perusahaan tersebut [2].

\section{A. Latar Belakang}

Salah satu organisasi bisnis atau perusahaan yang membutuhkan diadakannya BPR adalah PT Galeri Mata Indonesia (PT GMI). Sebagai salah satu perusahaan distribusi alat kesehatan lensa mata di Indonesia, PT GMI dituntut agar dapat memberikan pelayanan yang cepat kepada instansi kesehatan seperti rumah sakit dan klinik yang menyelenggarakan operasi bedah mata untuk ketersediaan stok lensa mata. Saat ini PT GMI sudah menerapkan $e$-business dalam proses bisnis yang dilakukan untuk memudahkan proses pemesanan dan distribusi produk ke pelanggan menggunakan sistem aplikasi berbasis web. Namun dikarenakan saat ini teknologi mobile application dinilai cukup efektif dalam mendukung proses bisnis, maka rencananya akan dilakukan perubahan bisnis proses dalam hal pemesanan dan pengantaran produk 
menggunakan aplikasi berbasis mobile. Sebelum sampai kepada proses perancangan aplikasi berbasis mobile application, perlu dilakukan perubahan konsep bisnis proses perusahaan dalam hal proses pemesanan dan distribusi produk. Tujuannya adalah agar Page|2 perubahan konsep aplikasi yang diterapkan nantinya dalam bisnis dapat efektif meningkatkan kinerja perusahaan dalam melayani pelanggan menjadi lebih baik dan tercapainya efisiensi biaya operasional perusahaan.

\section{B. Permasalahan}

Di dalam penelitian ini ada beberapa permasalahan yang akan dibahas yaitu sebagai berikut :

a. Bagaimana mengidentifikasi titik lemah pada proses yang ada saat ini dengan menggunakan analisa value chain dan critical success factor?

b. Bagaimana proses Business Process Reengineering di PT GMI dapat diterapkan dengan merancang alternatif baru melalui pemanfaatan perkembangan teknologi informasi berbasis mobile application?

c. Bagaimana rancangan design sistem distribusi produk berbasis mobile application ?

\section{Tujuan dan Manfaat Penelitian}

Tujuan dari pelaksanaan riset ini adalah untuk menghasilkan usulan proses bisnis dengan menerapkan rekayasa ulang proses bisnis menggunakan analisis value chain dan critical success factor untuk mengidentifikasi kegiatan utama dan aspek kritis yang dapat meningkatkan nilai tambah yang membuat perusahaan dapat lebih kompetitif.

Penelitian ini memiliki kontribusi dalam pengembangan bidang ilmu komputer yang terkait dengan pengembangan sistem informasi dengan produk penelitiannya adalah penerapan konsep Business Process Reengineering untuk mendukung perubahan konsep bisnis yang lebih baik dalam optimalisasi proses yang dilakukan perusahaan. Pengembangan sistem informasi idealnya didukung dengan perancangan konsep proses bisnis yang tepat, agar sistem yang dikembangkan dapat berjalan dengan efektif dan efisien serta memberikan nilai tambah bagi pengembangan bisnis perusahaan. Hasil penelitian juga akan menjadi literasi pengembangan ilmu pengetahuan dalam hal penerapan teknik rekayasa proses bisnis yang tepat di organisasi.

\section{TINJAUAN PUSTAKA}

\section{A. Business Process Reengineering}

Mengenal konsep business process reengineering berdasarkan suatu penelitian dapat dijelaskan sebagai suatu proses berfikir kembali (rethinking) dan proses perancangan kembali (redesign) secara mendasar (fundamental) untuk mendapatkan proses perbaikan yang memuaskan pemilik bisnis dan pengguna jasa bisnis atas kinerja perusahaan yang mencakup seluruh aspek produksi, kualitas produk, jumlah dan layanan terbaik [3].

\section{B. Value Chain Analysis}

Konsep value chain analysis dipopulerkan oleh seorang ahli Michael Porter dimana dalam konsep tersebut perusahaan dibagi menjadi dua bagian besar, yaitu kegiatan utama (primary activities) dan kegiatan pendukung (support activities). Kegiatan utama dibagi menjadi lima, yaitu logistik masuk (inbound logistics), manajemen operasi (operations), logistik keluar (outbound logistics), pemasaran dan penjualan (marketing and sales), serta pelayanan (service). Kegiatan pendukung dibagi empat, yaitu infrastruktur perusahaan (firm infrastructure), manajemen SDM (human resource management), teknologi (technology), serta pengadaan (procurement). Dimana rangkaian kegiatan tersebut dilakukan suatu perusahaan untuk menghasilkan produk atau jasa [4]

\section{Critical Success Factor}

Dalam mengembangkan suatu sistem informasi dalam tujuan untuk menghindari kegagalan maka ada beberapa faktor penting yang harus diperhatikan selama proses pengembangan sistem dan faktor-faktor penting tersebut disebut dengan critical success factor (CSF) dalam pengembangan sistem informasi [5].

Proyek pengembangan sistem informasi memiliki beberapa critical success factor diantaranya adalah: project strategy, project performance, project management process, project complexity dan project nature, plan and schedule sebagai aspek-aspek pendukung [6].

\section{Penelitian Terdahulu}

Salah satu manfaat dari penerapan Business Process Reengineering adalah adanya rekomendasi rancangan proses bisnis monitoring kontrak baru dengan menggunakan Sistem Monitoring Kontrak yang terintegrasi antar divisi sehingga menunjukkan penghematan waktu sebanyak 31,39\% - 44,51\% [7]. Business Process Reengineering merupakan sebuah pendekatan yang bertujuan untuk memperbaiki perusahaan secara signifikan. Penerapan BPR antara satu perusahaan dengan perusahaan lainnya akan berlainan meskipun metode yang digunakan sama, menyesuaikan dengan kondisi bisnis perusahaan [8]. Perubahan proses bisnis (Business Process Reengineering) dengan penerapan model e-Commerce menunjukkan perubahan usaha kearah yang lebih maju disamping tujuan utamanya adalah untuk efisiensi biaya dan waktu serta tentunya dalam peningkatan laba atau keuntungan perusahaan tersebut [2]. Pendekatan Business Process Reengineering mampu memberikan hasil yang dramatis untuk meningkatkan daya saing perusahaan untuk melakukan peningkatan dan perbaikan yang berkesinambungan. Kecepatan pelayanan, keakuratan pelayanan, kehandalan produk dan jasa, penghematan proses dalam mekanisme kontrol yang efektif adalah tujuan dari BPR [9]. Business Process Reengineering yang diterapkan pada 
instansi pelayanan masyarakat memberikan pengaruh dalam perubahan konsep proses bisnis untuk mengurangi biaya operasional, meningkatkan kinerja dan produktivitas pekerja dalam pelayanan kepada pelanggan [10].

Page | 3 Berdasarkan pemaparan mengenai hasil penelitian terdahulu mengenai Business Process Reengineering pada rancangan perubahan konsep proses bisnis di pengembangan sistem informasi kondisi riset terkini, maka dapat digambarkan pada block diagram berikut ini:

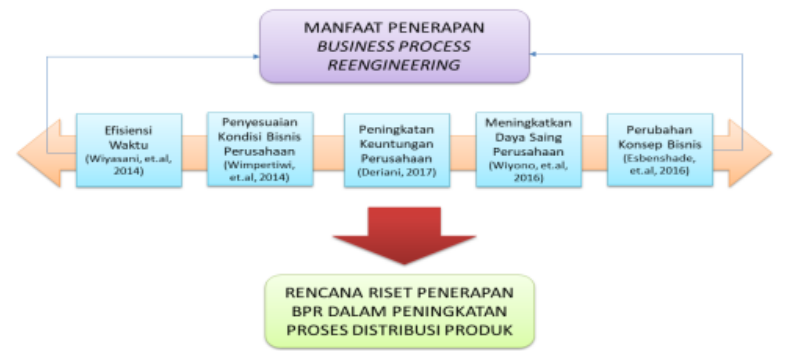

Gbr. 1 Rencana Penelitian Lanjutan Konsep Business Process Reengineering

Berdasarkan pemaparan hasil-hasil penelitian terdahulu mengenai topik Business Process Reengineering e-Business yang tergambar pada gambar 1. maka dapat dipahami beberapa hal sebagai berikut:

1) Business Process Reengineering e-Business dengan melakukan perubahan bisnis proses dapat meningkatkan efisiensi waktu operasional, peningkatan keuntungan perusahaan serta meningkatkan daya saing perusahaan dengan kompetitor.

2) Business Process Reengineering akan menyesuaikan dengan kondisi perusahaan serta perubahan konsep bisnis serta kebutuhan pengembangan e-Business antar satu dengan perusahaan lainnya dapat berbeda-beda, walau sudah menerapkan tahapan pengembangan Business Process Reengineering yang sesuai.

Oleh karena itu dengan memperhatikan hasil kajian penelitian sebelumnya, maka pemanfaatan konsep Business Process Reengineering diharapkan nantinya akan memberikan pengaruh positif bagi perusahaan untuk mempersingkat waktu komunikasi pemesanan barang, koordinasi aliran informasi antara pihak supplier, perusahaan, pelanggan dan kurir secara real time. Serta pengukuran service level agreement yang sesuai dengan kebutuhan tingkat kepuasan pelanggan terhadap pelayanan perusahaan dari aspek distribusi yang cepat serta kualitas produk yang baik.

\section{METODE PENELITIAN}

Dalam penelitian yang dilakukan ada beberapa tahapan analisa yang menjadi pedoman dalam menyelesaikan penelitian yaitu sebagai berikut:

\section{A. Kerangka Pemikiran Konseptual Penelitian}

Kerangka pemikiran konseptual adalah suatu tahapan bagi peneliti dalam melakukan proses penelitian dimulai dengan tahapan pengumpulan data dan observasi dalam mengidentifikasi permasalahan sampai dengan implementasi hasil penelitian [11].

Mengawali penelitian dilakukan beberapa proses primary research untuk menganalisis kondisi perusahaan dengan langkah-langkah sebagai berikut:

1. Observasi

Proses observasi yang dilakukan adalah dengan mengevaluasi proses distribusi yang saat ini berjalan di PT Galeri Mata Indonesia dari mulai proses pemesanan produk lensa mata kepada produsen sampai dengan produk diantarkan kepada pelanggan yaitu para instansi kesehatan seperti rumah sakit dan klinik.

2. Wawancara

Fungsi wawancara adalah untuk menggali informasi dan permasalahan yang terjadi pada sistem berjalan saat ini. Narasumber yang berperan dalam proses wawancara adalah pemilik PT GMI, pegawai administrasi sampai dengan pihak kurir yang bertugas mengantarkan produk.

3. Pengumpulan Data

Pengumpulan data yang dilakukan adalah dengan meminta dokumen administrasi seperti surat po, faktur pengantaran dan penerimaan barang serta dokumen-dokumen lainnya yang terkait dengan proses distribusi produk lensa mata di PT GMI. Hal ini dilakukan untuk memudahkan identifikasi kebutuhan fungsional pada usulan sistem yang akan disampaikan melalui analisa Business Process Reengineering.

Secara keseluruhan penggambaran kerangka pemikiran konseptual dalam penelitian adalah sebagai berikut:

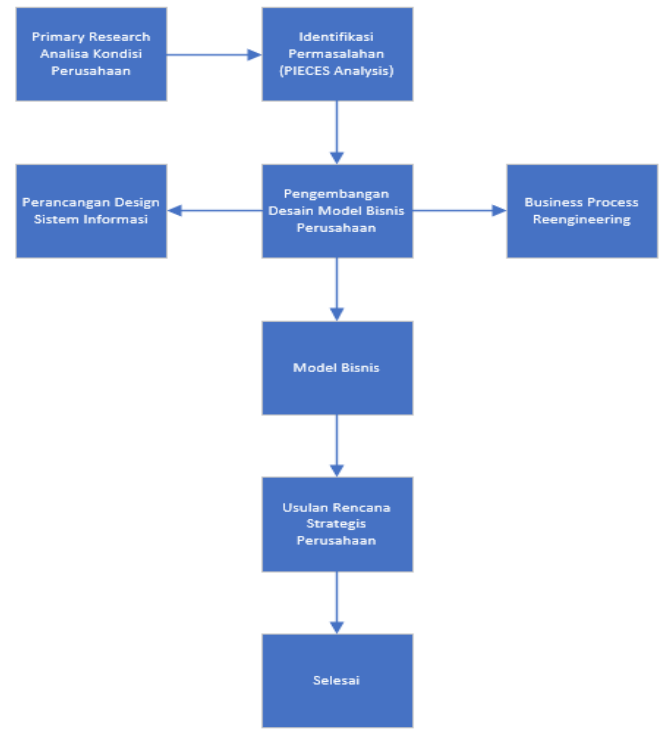

Gbr. 2 Konseptual Penelitian 
Dari penggambaran diatas dapat dijelaskan bahwa target pada penelitian adalah menghasilkan rancangan model bisnis yang tepat dengan mengimplementasikan business process reengineering dan juga melakukan redesign sistem informasi sehingga membantu Page | 4 perusahaan dalam hal usulan rencana strategi perusahaan.

\section{B. Diagram Alir Penelitian}

Dari kerangka konseptual penelitian yang sudah dijelaskan sebelumnya, maka dapat dijabarkan lebih detail kedalam diagram alir penelitian sebagai berikut:

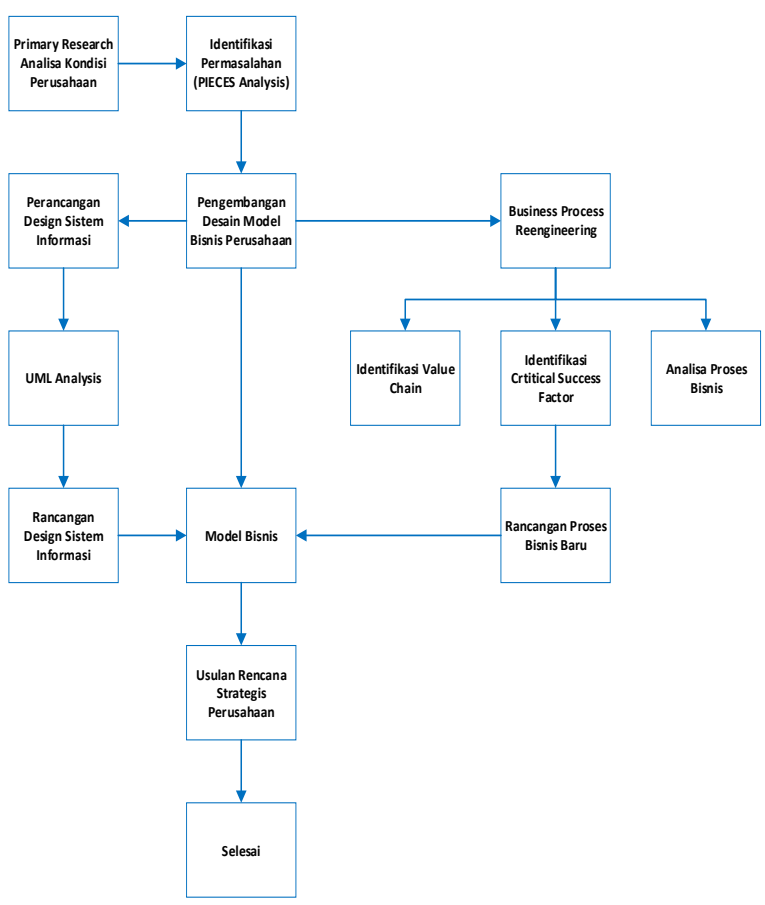

Gbr. 3 Diagram Alir Penelitian

Pada diagram alir penelitian diatas dapat dilihat bahwa untuk dapat merekayasa bisnis proses perlu dilakukan tahapan identifikasi dengan menggunakan metode analisa value chain dan critical success factor agar mendapatkan rancangan proses bisnis baru yang sesuai dengan kebutuhan pengembangan bisnis perusahaan.

\section{IV.HASIL DAN PEMBAHASAN}

\section{A. Analisa Sistem Berjalan}

Berikut ini adalah analisa sistem berjalan dari proses bisnis saat ini :

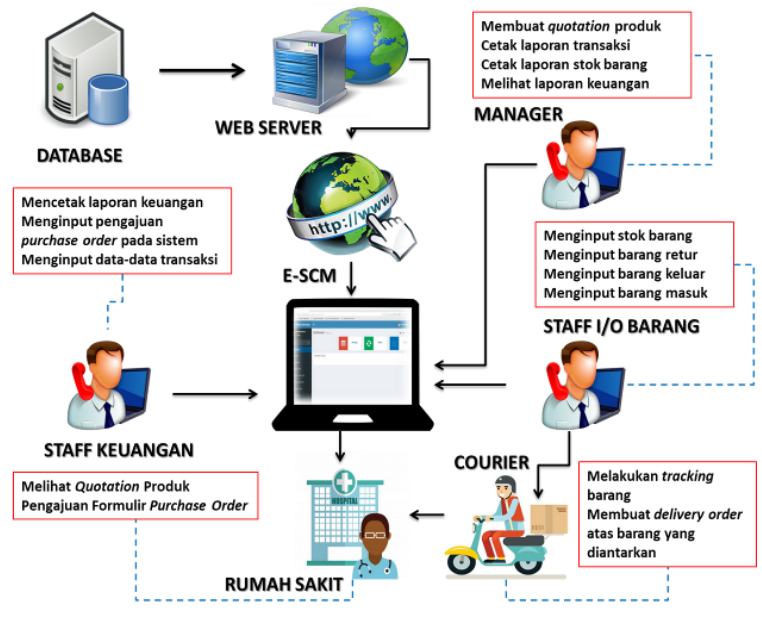

Gbr. 4 Analisa Sistem Berjalan

Pada sistem yang sedang berjalan saat ini, PT Galeri Mata Indonesia sudah memiliki sistem aliran rantai pasok berbasis web yang menghubungkan informasi antara PT GMI, pelanggan seperti rumah sakit, namun belum terintegrasi dengan pemantauan barang yang dilakukan oleh pihak kurir.

\section{B. Identifikasi Permasalahan}

Identifikasi permasalahan dengan pendekatan Metode PIECES. Metode PIECES dalam suatu penelitian yang dilakukan memberikan kemudahan analisa permasalahan dengan sudut pandang beberapa aspek yaitu: analisa system performance, information, economic, control, efficiency, dan service [12].

Adapun identifikasi permasalahan ditinjau dari analisa PIECES adalah sebagai berikut:

TABEL I

ANALISA PIECES

\begin{tabular}{|l|l|l|}
\hline \multicolumn{1}{|c|}{ Aspek } & Permasalahan & \multicolumn{1}{c|}{ Solusi } \\
\hline Performanc & - Lambat karena & - Merubah \\
& informasi & proses bisnis \\
& pengiriman barang & untuk \\
& masih dilakukan & konfirmasi \\
& via telepon & pengiriman \\
& - Kurang akurat & berbasis \\
& karena konfirmasi & mobile \\
& delivery barang & application \\
& tidak dapat & - Merubah \\
& dilakukan secara & proses \\
& real time oleh kurir & konfirmasi \\
& & pengiriman \\
& & langsung \\
& & melalui \\
& & aplikasi \\
\hline Information & - Belum & - Sistem e- \\
& komprehensif & SCM yang \\
& karena informasi & saat \\
& pengantaran & digunakan \\
& produk belum & akan \\
& menggunakan 1 & dikembangka \\
& sistem yang sama & n dalam versi \\
& & apps untuk \\
& & pengiriman \\
\hline
\end{tabular}




\begin{tabular}{|c|c|c|c|}
\hline & Economic & $\begin{array}{l}\text { Membutuhkan } \\
\text { extra cost dalam } \\
\text { pembiayaan cetak } \\
\text { dokumen delivery } \\
\text { order }\end{array}$ & $\begin{array}{l}\text { - Perubahan } \\
\text { proses } \\
\text { crosscheck } \\
\text { delivery order } \\
\text { via aplikasi }\end{array}$ \\
\hline \multirow[t]{3}{*}{ Page | 5} & Control & $\begin{array}{l}\text { - Sulit melakukan } \\
\text { pengawasan status } \\
\text { pengiriman secara } \\
\text { up to date }\end{array}$ & $\begin{array}{l}\text { - Perubahan } \\
\text { bisnis proses } \\
\text { QC dilakukan } \\
\text { bersamaan }\end{array}$ \\
\hline & Efficiency & $\begin{array}{l}\text { - Sistem belum } \\
\text { integrasi ke proses } \\
\text { pengiriman } \\
\text { sehingga kurang } \\
\text { efisien untuk } \\
\text { crosscheck data }\end{array}$ & $\begin{array}{l}\text { Usulan } \\
\text { perancangan } \\
\text { sistem yang } \\
\text { mengintegrasi } \\
\text { kan proses } \\
\text { delivery } \\
\text { system }\end{array}$ \\
\hline & Service & $\begin{array}{l}\text { - Pelayanan PT GMI } \\
\text { belum maksimal } \\
\text { dikarenakan } \\
\text { pelanggan belum } \\
\text { dapat memantau } \\
\text { proses pengiriman } \\
\text { barang }\end{array}$ & $\begin{array}{l}\text { - Usulan } \\
\text { perubahan } \\
\text { proses } \\
\text { pelanggan } \\
\text { dapat tracking } \\
\text { pengiriman } \\
\text { via aplikasi, } \\
\text { sehingga } \\
\text { dapat diukur } \\
\text { periode } \\
\text { pengiriman }\end{array}$ \\
\hline
\end{tabular}

C. Kebutuhan Fungsional dan Non Fungsional

Adapun kebutuhan fungsional dan non fungsional dari usulan perubahan bisnis proses pada sistem yang akan diusulkan adalah sebagai berikut:

TABEL II

KEBUTUHAN FUNGSIONAL DAN NON FUNGSIONAL USULAN PERUBAHAN BISNIS PROSES SISTEM

\begin{tabular}{|c|l|}
\hline No & \multicolumn{1}{|c|}{ Kebutuhan Fungsional } \\
\hline 1 & $\begin{array}{l}\text { Sistem dapat melakukan order pemesanan } \\
\text { pengantaran produk via kurir melalui aplikasi. }\end{array}$ \\
\hline 2 & $\begin{array}{l}\text { Kurir yang sudah mendaftarkan kerja sama dengan } \\
\text { PT GMI dapat memilih order pengantaran produk } \\
\text { disesuaikan dengan kemampuan akses lokasi. }\end{array}$ \\
\hline 3 & $\begin{array}{l}\text { Biaya tarif pengantaran dapat terukur melalui } \\
\text { sistem sesuai dengan informasi jarak tempuh dari } \\
\text { lokasi pengantaran produk. }\end{array}$ \\
\hline 4 & $\begin{array}{l}\text { Sistem dapat mengidentifikasi keberadaan atau } \\
\text { posisi pergerakan kurir saat mengantarkan produk. }\end{array}$ \\
\hline 5 & $\begin{array}{l}\text { Alamat pengiriman dan para pelanggan PT GMI } \\
\text { dapat didaftarkan di sistem sehingga memudahkan } \\
\text { dalam proses pengantaran produk. }\end{array}$ \\
\hline 6 & $\begin{array}{l}\text { Pelanggan dapat memantau pergerakan pengiriman } \\
\text { produk. }\end{array}$ \\
\hline 7 & PT GMI dapat memberikan evaluasi kinerja kurir. \\
\hline 8 & $\begin{array}{l}\text { Pelanggan dapat memberikan feedback pengiriman } \\
\text { produk. }\end{array}$ \\
\hline 10 & $\begin{array}{l}\text { SLA dari target pengiriman produk antar kurir } \\
\text { dapat terukur dengan baik. }\end{array}$ \\
\hline No & \multicolumn{1}{|c|}{ Kebutuhan Non Fungsional } \\
\hline 1 & Kinerja sistem cepat. \\
\hline 2 & Validasi data sistem akurat. \\
\hline 3 & Keamanan sistem terjamin dengan baik. \\
\hline & \\
\hline
\end{tabular}

\section{Identifikasi Value Chain}

Value chain analysis diperkenalkan oleh Michael Porter pada tahun 1985 merupakan strategi yang digunakan untuk menganalisis kegiatan internal perusahaan. Kegiatan internal perusahaan yang dimaksud terkait dengan aktifitas pendukung dalam aspek firm infrastructure, human resource management, information technology dan procurement. Lalu aktifitas utama terkait dengan kegiatan yang berhubungan dengan aspek inbound logistics, operations, outbound logistics, marketing \& sales dan services [13]. Berikut ini adalah hasil identifikasi value chain analysis dari PT GMI:

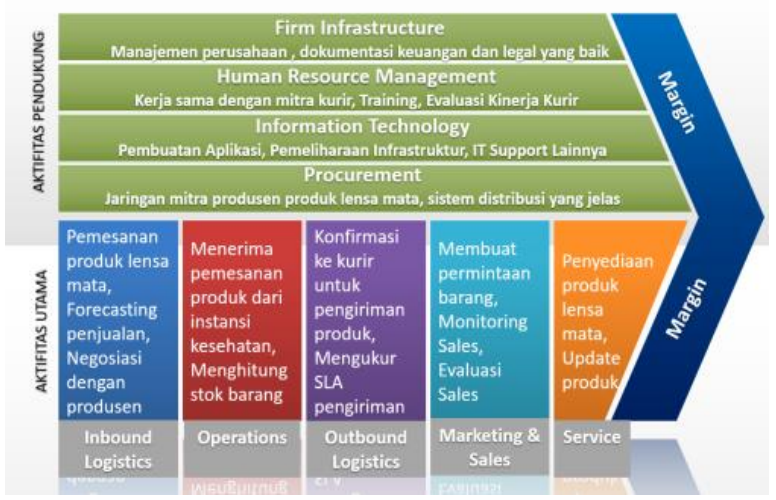

Gbr. 5 Value Chain Analysis

\section{E. Identifikasi Critical Success Factor}

Aspek Critical Success Factor (CSF) erat kaitannya dengan KPI (Key Performance Indicator). CSF adalah aspek yang perlu diperhatikan oleh perusahaan untuk menentukan tercapainya sebuah misi organisasi, sedangkan KPI adalah alat ukur kuantitas untuk mencapai CSF tersebut [8].

Berikut ini adalah informasi hasil analisis CSF dan KPI serta Model Kinerja pada PT GMI yang dijelaskan pada Tabel. 3 :

TABEL III

ANALISIS CSF DAN KPI SERTA MODEL KINERJA

\begin{tabular}{|c|c|l|c|}
\hline No & CSF & \multicolumn{1}{|c|}{ KPI } & Target \\
\hline \multirow{5}{*}{1} & \multirow{4}{*}{ SDM } & Jumlah rekrutmen baru & $100 \%$ \\
\cline { 3 - 4 } & & Produktivitas karyawan & $45 \%$ \\
\cline { 3 - 4 } & $\begin{array}{l}\text { Tingkat } \text { employee } \\
\text { turnover }\end{array}$ & Max 1\% \\
\cline { 3 - 4 } & $\begin{array}{l}\text { Biaya pegawai dibanding } \\
\text { dengan total cost }\end{array}$ & Max 8\% \\
\cline { 3 - 4 } & Profit per pegawai & 50 Juta \\
\cline { 3 - 4 } & Training pegawai & $\begin{array}{c}1-3 / \\
\text { Tahun }\end{array}$ \\
\hline \multirow{5}{*}{2} & Marketing & $\begin{array}{l}\text { Pertumbuhan penjualan } \\
\text { dibandingkan tahun lalu }\end{array}$ & $20 \%$ \\
\cline { 3 - 4 } & Market share & $25 \%$ \\
\cline { 3 - 4 } & Kepuasan Customer & 5 \\
\cline { 3 - 4 } & $\begin{array}{l}\text { Jumlah Pengembangan } \\
\text { Produk }\end{array}$ & $\begin{array}{c}1-3 \\
\text { Produk/ } \\
\text { Tahun }\end{array}$ \\
\cline { 3 - 4 } & & $\begin{array}{l}\text { Supply product dari } \\
\text { produsen }\end{array}$ & $100 \%$ \\
\cline { 3 - 4 } & Product availability in & $95 \%$ \\
\hline
\end{tabular}




\begin{tabular}{|c|c|c|c|c|}
\hline & & & market & \\
\hline & & & Diskon produk & $1-10 \%$ \\
\hline & & & $\begin{array}{l}\text { Penyelesaian complain } \\
\text { pelanggan secara tuntas }\end{array}$ & $\begin{array}{l}\operatorname{Max} 24 \\
\text { jam }\end{array}$ \\
\hline \multirow{13}{*}{ Page | 6} & \multirow{7}{*}{3} & \multirow{7}{*}{ IT } & $\begin{array}{l}\text { Sistem Jaringan } \\
\text { Komputer }\end{array}$ & $99 \%$ \\
\hline & & & Integrasi Sistem & $70 \%$ \\
\hline & & & $\begin{array}{l}\text { Implementasi Sesuai } \\
\text { Rencana }\end{array}$ & $95 \%$ \\
\hline & & & $\begin{array}{l}\text { Pengembangan Aplikasi } \\
\text { Baru }\end{array}$ & $\begin{array}{c}2 / \\
\text { Tahun }\end{array}$ \\
\hline & & & Kepuasan Customer & 4 \\
\hline & & & $\begin{array}{l}\text { ROI Dari Program } \\
\text { Aplikasi }\end{array}$ & $200 \%$ \\
\hline & & & $\begin{array}{l}\text { Jumlah Kurir Yang } \\
\text { Menggunakan Integrasi } \\
\text { Sistem }\end{array}$ & 10 Mitra \\
\hline & \multirow{6}{*}{4} & \multirow{6}{*}{ Finance } & Operating Cost Ratio & $40 \%$ \\
\hline & & & $\begin{array}{l}\text { Rata-rata Ketersediaan } \\
\text { Cash Setiap Bulan }\end{array}$ & 10 Juta \\
\hline & & & $\begin{array}{l}\text { Pemrosesan Piutang } \\
\text { Tepat Waktu }\end{array}$ & $100 \%$ \\
\hline & & & $\begin{array}{l}\text { Laporan Keuangan } \\
\text { Disajikan Akurat }\end{array}$ & $100 \%$ \\
\hline & & & $\begin{array}{l}\text { Laporan Keuangan } \\
\text { Disajikan Tepat Waktu }\end{array}$ & $100 \%$ \\
\hline & & & Return on Asset & $100 \%$ \\
\hline
\end{tabular}

Informasi pada table diatas menjelaskan identifikasi CSF dengan target KPI yang harus dapat dipenuhi pada kinerja operasional bisnis PT GMI untuk menambah nilai dan keuntungan perusahaan.

\section{F. Business Process Reengineering}

Analisa Business Process Reengineering akan mengevaluasi dari aspek rethink (peninjauan kembali terhadap target KPI), aspek redesign (bagaimana mendesain ulang strategi untuk mencapai target) serta aspek retool (bagaimana mengelola alat bantu yang dapat mendukung pencapaian target KPI).

TABEL IV

ANALISA KPI, RETHINK, REDESIGN, RETOOL

\begin{tabular}{|c|c|c|c|c|c|}
\hline $\begin{array}{l}\mathbf{N} \\
\mathbf{O}\end{array}$ & $\begin{array}{c}\text { CS } \\
\text { F }\end{array}$ & KPI & Rethink & Redesign & Retool \\
\hline \multirow{6}{*}{1} & \multirow{6}{*}{$\begin{array}{l}\text { SD } \\
\mathrm{M}\end{array}$} & $\begin{array}{l}\text { Jumlah } \\
\text { rekrutmen baru }\end{array}$ & \multirow{6}{*}{$\begin{array}{l}\text { Peninjau } \\
\text { an } \\
\text { kembali } \\
\text { kinerja } \\
\text { para } \\
\text { karyawa } \\
\text { n }\end{array}$} & \multirow{6}{*}{$\begin{array}{l}\text { Memberikan } \\
\text { pelatihan } \\
\text { secara } \\
\text { berkala } \\
\text { kepada } \\
\text { karyawan. } \\
\text { Sosialisasi } \\
\text { optimalisasi } \\
\text { perangkat } \\
\text { kerja, melatih } \\
\text { ide, } \\
\text { kreatifitas } \\
\text { karyawan. } \\
\text { Efisiensi } \\
\text { produktifitas } \\
\text { operasional. }\end{array}$} & \multirow{6}{*}{$\begin{array}{l}\text { Evaluasi } \\
\text { secara } \\
\text { berkala } \\
\text { sesuai } \\
\text { prosedur } \\
\text { perusahaan }\end{array}$} \\
\hline & & $\begin{array}{l}\text { Produktivitas } \\
\text { karyawan }\end{array}$ & & & \\
\hline & & $\begin{array}{l}\text { Tingkat } \\
\text { employee } \\
\text { turnover }\end{array}$ & & & \\
\hline & & $\begin{array}{l}\text { Biaya pegawai } \\
\text { dibanding } \\
\text { dengan total } \\
\text { cost }\end{array}$ & & & \\
\hline & & $\begin{array}{l}\text { Profit per } \\
\text { pegawai }\end{array}$ & & & \\
\hline & & $\begin{array}{l}\text { Training } \\
\text { pegawai }\end{array}$ & & & \\
\hline \multirow{4}{*}{2} & \multirow{4}{*}{$\begin{array}{l}\text { Ma } \\
\text { rket } \\
\text { ing }\end{array}$} & $\begin{array}{l}\text { Pertumbuhan } \\
\text { penjualan } \\
\text { dibandingkan } \\
\text { tahun lalu }\end{array}$ & \multirow{4}{*}{$\begin{array}{l}\text { Peninjau } \\
\text { an } \\
\text { kembali } \\
\text { kepuasa } \\
\mathrm{n} \\
\text { custome } \\
r \text { dan } \\
\text { market }\end{array}$} & \multirow{4}{*}{$\begin{array}{l}\text { Perancangan } \\
\text { proses ulang } \\
\text { sistem } \\
\text { marketing } \\
\text { dan proses } \\
\text { bisnis } \\
\text { perusahaan. }\end{array}$} & \multirow{4}{*}{$\begin{array}{l}\text { Memaduka } \\
\mathrm{n} \text { proses } \\
\text { pemasaran } \\
\text { dengan } \\
\text { dukungan } \\
\text { teknologi } \\
\text { yang tepat. }\end{array}$} \\
\hline & & Market share & & & \\
\hline & & $\begin{array}{l}\text { Kepuasan } \\
\text { Customer }\end{array}$ & & & \\
\hline & & Jumlah & & & \\
\hline
\end{tabular}

\begin{tabular}{|c|c|c|c|c|c|}
\hline & & $\begin{array}{l}\text { Pengembangan } \\
\text { Produk }\end{array}$ & \multirow{5}{*}{$\begin{array}{l}\text { share. } \\
\text { Menguk } \\
\text { ur } \\
\text { perkemb } \\
\text { angan } \\
\text { competit } \\
\text { or dan } \\
\text { peluang } \\
\text { perkemb } \\
\text { angan } \\
\text { bisnis } \\
\text { jangka } \\
\text { panjang. }\end{array}$} & & \\
\hline & & $\begin{array}{l}\text { Supply product } \\
\text { dari produsen }\end{array}$ & & & \\
\hline & & $\begin{array}{l}\text { Product } \\
\text { availability in } \\
\text { market }\end{array}$ & & & \\
\hline & & Diskon produk & & & \\
\hline & & $\begin{array}{l}\text { Penyelesaian } \\
\text { complain } \\
\text { pelanggan } \\
\text { secara tuntas }\end{array}$ & & & \\
\hline & \multirow{7}{*}{ IT } & $\begin{array}{l}\text { Sistem Jaringan } \\
\text { Komputer }\end{array}$ & \multirow{7}{*}{$\begin{array}{l}\text { Peninjau } \\
\text { an } \\
\text { kembali } \\
\text { proses } \\
\text { delivery } \\
\text { order } \\
\text { untuk } \\
\text { dapat } \\
\text { diintegr } \\
\text { asikan } \\
\text { dengan } \\
\text { sistem } \\
\text { informa } \\
\text { si saat } \\
\text { ini. }\end{array}$} & \multirow{7}{*}{$\begin{array}{l}\text { Pengadaan } \\
\text { kembali } \\
\text { perangkat } \\
\text { lunak yang } \\
\text { belum } \\
\text { memenuhi } \\
\text { standart. } \\
\text { Merancang } \\
\text { ulang sistem } \\
\text { informasi } \\
\text { yang } \\
\text { terintegrasi } \\
\text { dengan } \\
\text { proses } \\
\text { delivery } \\
\text { order. }\end{array}$} & \multirow{7}{*}{$\begin{array}{l}\text { Evaluasi } \\
\text { design } \\
\text { system } \\
\text { serta } \\
\text { infrastrukt } \\
\text { ur } \\
\text { teknologi } \\
\text { yang } \\
\text { digunakan. }\end{array}$} \\
\hline & & Integrasi Sistem & & & \\
\hline & & $\begin{array}{l}\text { Implementasi } \\
\text { Sesuai Rencana }\end{array}$ & & & \\
\hline & & $\begin{array}{l}\text { Pengembangan } \\
\text { Aplikasi Baru }\end{array}$ & & & \\
\hline & & $\begin{array}{l}\text { Kepuasan } \\
\text { Customer }\end{array}$ & & & \\
\hline & & $\begin{array}{l}\text { ROI Dari } \\
\text { Program } \\
\text { Aplikasi }\end{array}$ & & & \\
\hline 3 & & $\begin{array}{l}\text { Jumlah Kurir } \\
\text { Yang } \\
\text { Menggunakan } \\
\text { Integrasi Sistem }\end{array}$ & & & \\
\hline \multirow{6}{*}{4} & \multirow{6}{*}{$\begin{array}{l}\text { Fin } \\
\text { anc } \\
\text { e }\end{array}$} & $\begin{array}{l}\text { Operating Cost } \\
\text { Ratio }\end{array}$ & \multirow{6}{*}{$\begin{array}{l}\text { Peninjau } \\
\text { an } \\
\text { kembali } \\
\text { kepada } \\
\text { laporan } \\
\text { keuanga } \\
\mathrm{n} \text { dan } \\
\text { operatin } \\
\text { g cost }\end{array}$} & \multirow{6}{*}{$\begin{array}{l}\text { Merancang } \\
\text { sistem } \\
\text { keuangan } \\
\text { yang } \\
\text { terintegrasi } \\
\text { dengan } \\
\text { sistem e- } \\
\text { SCM yang } \\
\text { digunakan } \\
\text { untuk } \\
\text { memudahkan } \\
\text { evaluasi } \\
\text { operasional. }\end{array}$} & \multirow{6}{*}{$\begin{array}{l}\text { Evaluasi } \\
\text { rutin untuk } \\
\text { mengecek } \\
\text { laporan } \\
\text { keuangan } \\
\text { dan } \\
\text { operating } \\
\text { cost }\end{array}$} \\
\hline & & $\begin{array}{l}\text { Rata-rata } \\
\text { Ketersediaan } \\
\text { Cash Setiap } \\
\text { Bulan } \\
\end{array}$ & & & \\
\hline & & $\begin{array}{l}\text { Pemrosesan } \\
\text { Piutang Tepat } \\
\text { Waktu }\end{array}$ & & & \\
\hline & & $\begin{array}{l}\text { Laporan } \\
\text { Keuangan } \\
\text { Disajikan } \\
\text { Akurat }\end{array}$ & & & \\
\hline & & $\begin{array}{l}\text { Laporan } \\
\text { Keuangan } \\
\text { Disajikan Tepat } \\
\text { Waktu }\end{array}$ & & & \\
\hline & & Return on Asset & & & \\
\hline
\end{tabular}

\section{G. Rancangan Model Bisnis}

Salah satu pemodelan bisnis yang cukup komprehensif menurut Alexander Osterwalder dan Yves Pigneur dalam buku nya Business Model Generation bahwa ada Sembilan blok bangunan dasar pada sebuah bisnis model yang memperlihatkan cara berpikir tentang bagaimana sebuah perusahaan menghasilkan uang, gabungan kesembilan blok tersebut mencakup empat bidang utama pada suatu bisnis, yaitu pelanggan, penawaran, infrastruktur, dan kelangsungan finansial. Dalam pembagiannya terdiri atas 9 blok bisnis yang saling terkait, yaitu : 1 . Customer Segment, 2. Value Proposition, 3. Channel, 4. Customer Relationship, 5. Revenue Stream, 6. Key Partner, 7. Key Activities, 8. Key Resource dan 9. Cost Structure [14].

Berikut ini adalah penggambaran hasil analisa dengan implementasi metode business model canvas yang dapat menjadi pertimbangan penentuan strategi bisnis yang tepat pada PT Galeri Mata Indonesia : 


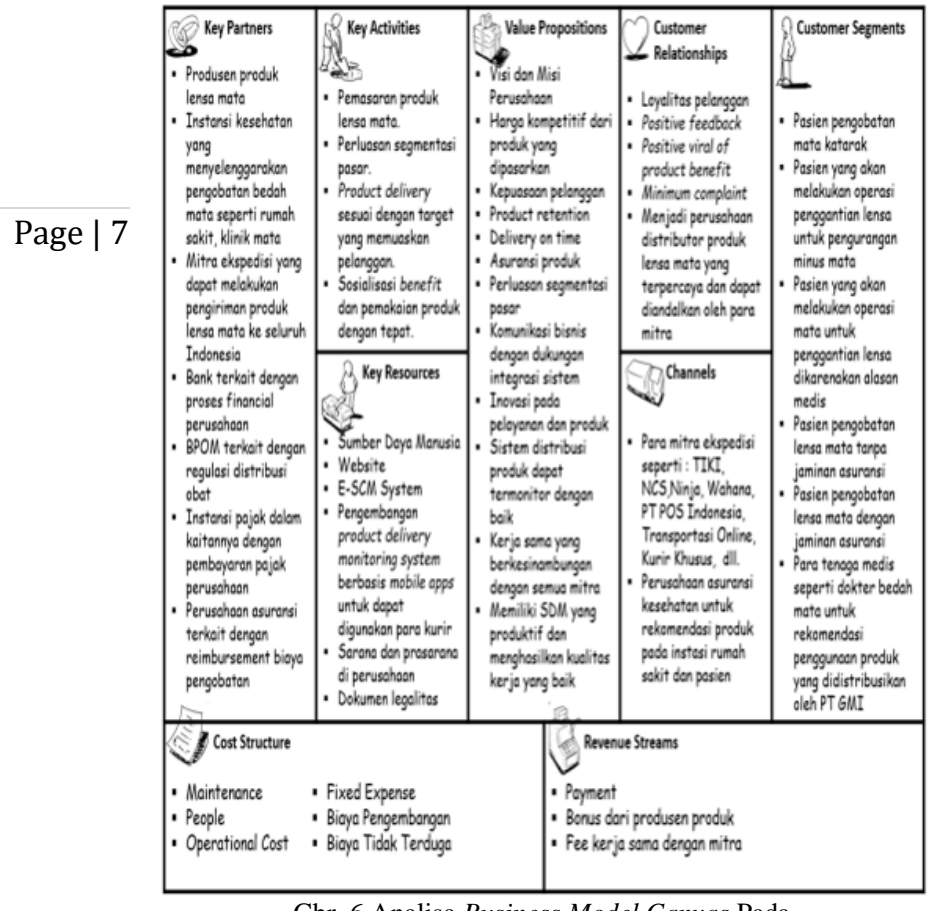

Gbr. 6 Analisa Business Model Canvas Pada PT Galeri Mata Indonesia

Berdasarkan analisa pada gambar 6. tersebut dapat dipahami bahwa value proposition suatu perusahaan dapat dicapai apabila didukung dengan aspek-aspek lainnya. Misalnya untuk mencapai target delivery on time, maka perlu dipertimbangkan strategi pada aspek key resources bahwa harus adanya inovasi dalam hal pengembangan product delivery monitoring system berbasis mobile apps yang dapat memudahkan transaksi pembelian produk dan monitoring delivery produk sampai nanti diterima oleh instansi kesehatan untuk digunakan oleh pasien pengobatan mata dalam kondisi baik dan tepat waktu.

\section{H. Rancangan Design Aplikasi}

Dalam merancang desain sistem informasi dapat menggunakan Teknik UML (Unified Modelling Language). Salah satunya menggunakan metode analisa use case diagram. Use case diagram digunakan untuk memudahkan perancang sistem informasi untuk menggambarkan secara ringkas siapa yang menggunakan sistem dan apa saja yang bias dilakukannya, selain itu tergambar juga gambaran singkat hubungan antara use case, actor dan sistem [15].

Berikut ini adalah penggambaran use case diagram untuk rencana perubahan proses bisnis delivery order system pada PT GMI berbasis mobile application :

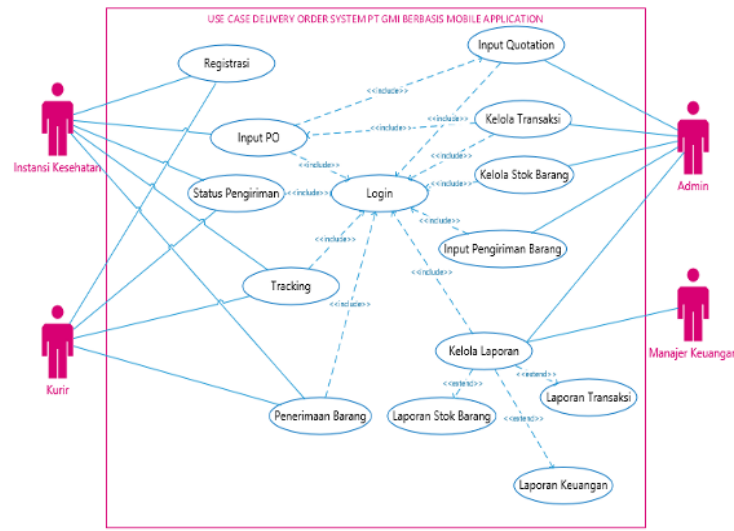

Gbr. 7 Use Case Diagram Order System PT GMI Berbasis Mobile Application

Adapun perancangan desain sistem informasi yang tergambar pada use case diagram pada gambar 7 . adalah sebagai berikut :

1. Menu Login

Seluruh fungsi dalam sistem informasi dapat diakses apabila melakukan aktivasi user name dan password melalui menu login seperti tampilan di bawah ini :

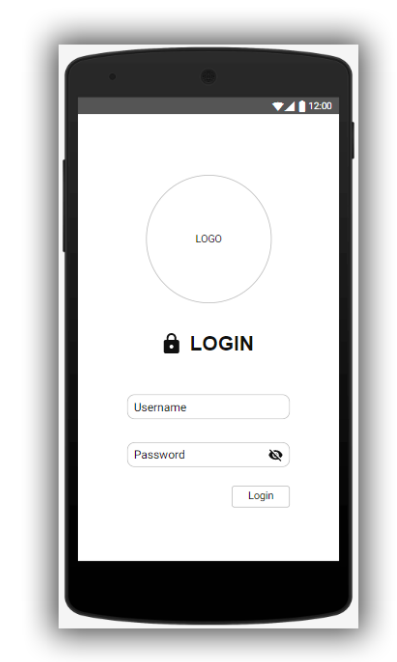

Gbr. 8 Rancangan Design Menu Login

\section{Menu Home}

Melalui sistem aplikasi delivery order system yang akan dirancang melalui versi mobile application nantinya user akan dapat melakukan pemesanan barang, pengembalian (return), cek stok, melihat transaksi, laporan serta melakukan tracking pengiriman. 
Page | 8
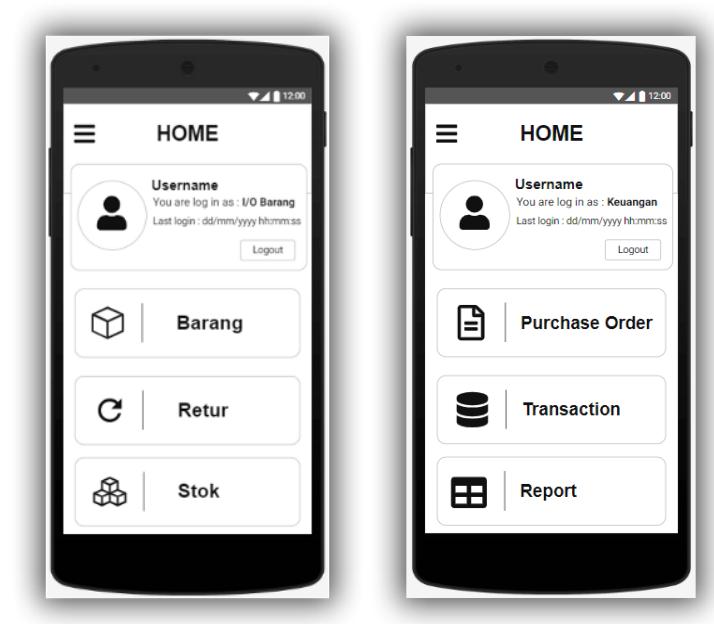

Gbr. 9 Rancangan Design Menu Home

3. Menu Barang

Pada saat memilih menu Barang, maka pengguna akhir akan diminta untuk menginput quotation form yang tujuannya adalah melakukan permintaan informasi produk yang mau dipesan. Informasi ini berada pada inputan data di Quotation Form seperti tampilan dibawah ini :

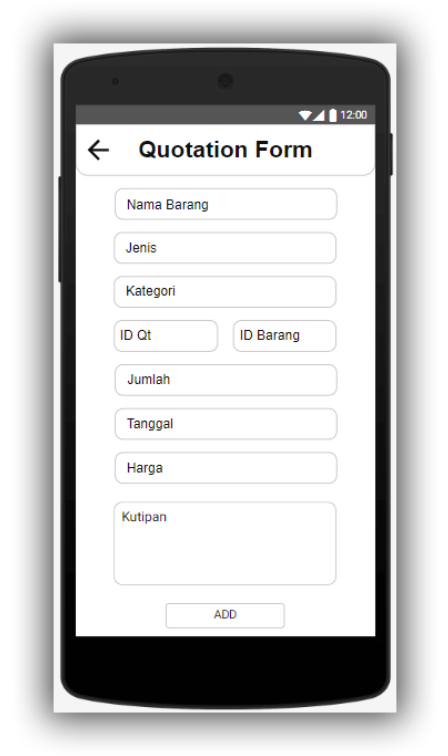

Gbr. 10 Rancangan Design Quotation Form

Data-data yang perlu diisi adalah nama barang, jenis, kategori, id transaksi, id barang, jumlah, tanggal pemesanan, total harga dan catatan khusus jika diperlukan.

\section{Menu Transaction}

Pada saat memilih menu Transaction rencananya akan dirancang design list transaction yang pernah dilakukan untuk instansi kesehatan atau seluruh transaksi dapat dilihat bagi admin dan bagian keuangan dari PT GMI.

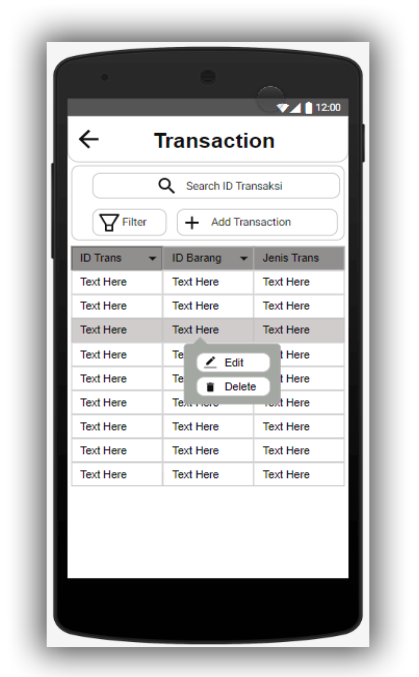

Gbr. 10 Rancangan Design Menu Transaction

Pada menu Transaction kewenangan edit dan delete data ada pada admin staff PT GMI yang bertugas mengelola aplikasi.

5. Menu Purchase Order

Apabila berdasarkan informasi di quotation sudah jelas dan instansi kesehatan seperti rumah sakit menyetujui dapat langsung melakukan pemesanan produk di menu purchase order

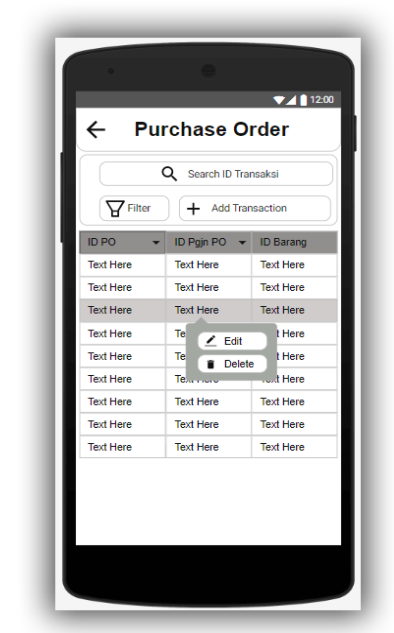

Gbr. 11 Rancangan Design Menu Purchase Order

Informasi pada purchase order ini akan menjadi dasar bagi PT GMI untuk menindaklanjuti pemesanan produk kepada para produsen produk lensa mata sesuai dengan informasi produk yang dipesan oleh instansi kesehatan.

6. Menu Report

Pada usulan pengembangan rancangan sistem informasi dari sistem e-SCM yang telah dikembangkan selanjutnya untuk laporan juga dapat diakses informasinya melalui mobile application. Adapun laporan yang dapat diakses 
adalah laporan keuangan, laporan transaksi dan laporan stok barang.

Page | 9

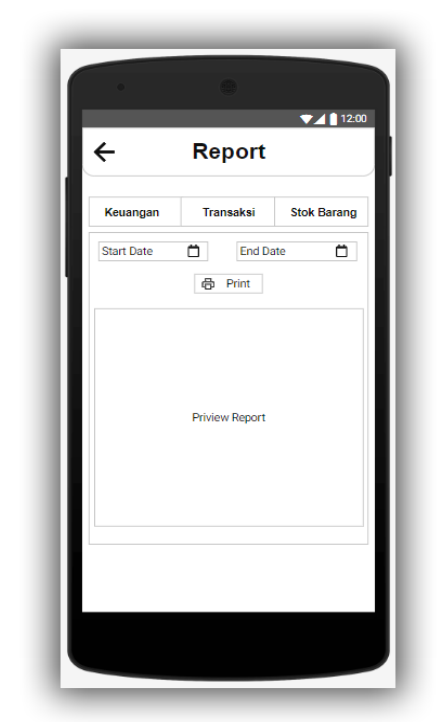

Gbr. 12 Rancangan Design Menu Report

Laporan ini sangat diperlukan oleh bagian keuangan PT GMI untuk memperhitungkan arus kas, profit dan menyesuaikan laporan keuangan perusahaan pada sistem keuangan perusahaan.

7. Menu Pengiriman Barang

Pada menu pengiriman barang diinput oleh staff admin dari PT GMI untuk mengirimkan produk lensa mata sesuai dengan purchase order yang disampaikan oleh instansi kesehatan.

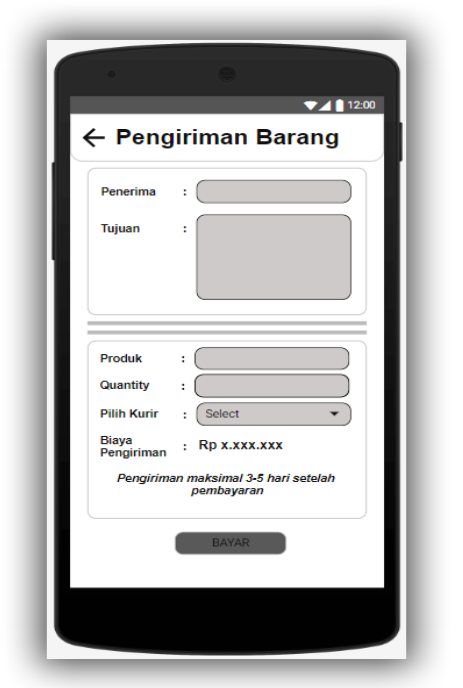

Gbr. 13 Rancangan Design Menu Pengiriman Barang

8. Menu Tracking Pengiriman Barang

Untuk mempermudah pelacakan keberadaan kurir yang mengirimkan barang maka pada perancangan sistem informasi delivery order system PT GMI berbasis mobile application dilengkapi dengan sistem tracking yang terhubung dengan GPS yang ada pada smartphone dari kurir yang mengantarkan produk.

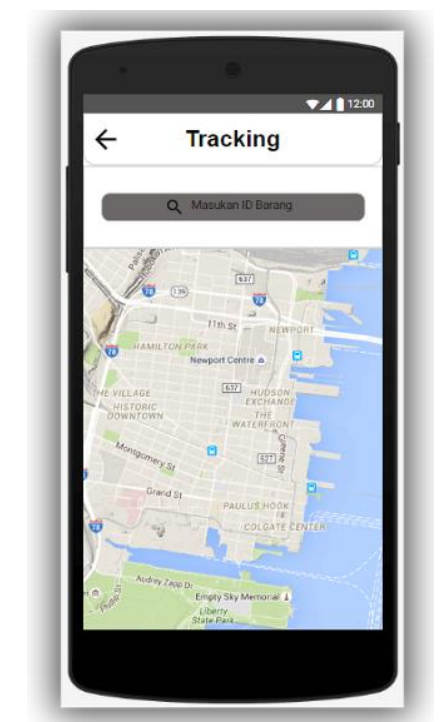

Gbr. 14 Rancangan Design Menu Tracking Pengiriman Barang

9. Menu Status Pengiriman Barang

Menu status pengiriman barang diperlukan untuk mengetahui apakah produk lensa mata sudah diterima atau belum oleh instansi kesehatan yang dituju oleh PT GMI. Status pengiriman ini akan diperbaharui datanya oleh kurir yang bertugas mengirimkan produk.

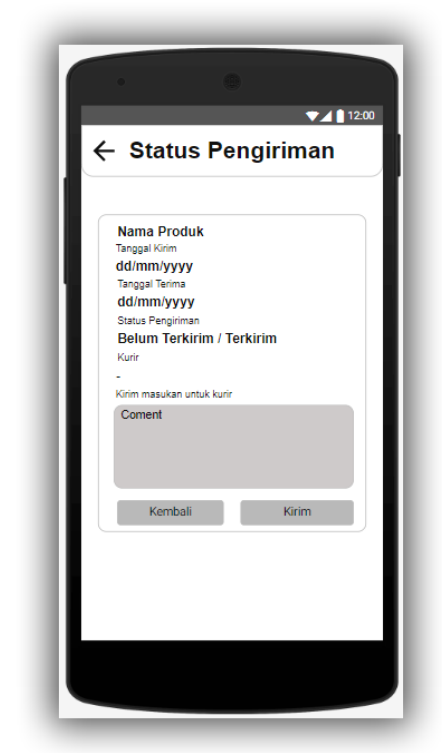

Gbr. 15 Rancangan Design Menu Status Pengiriman Produk

10. Menu Penerimaan Barang

Apabila instansi kesehatan seperti rumah sakit sudah menerima produk lensa mata dari kurir maka selanjutnya, diperlukan proses update status penerimaan produk oleh pihak penerima produk dengan memfoto produk yang diterima serta memberikan rating terhadap kinerja kurir yang mengantarkan produk. Kurir pun dapat mengecek 
status penerimaan barang dan feedback dari pelanggan termasuk complaint jika ada.

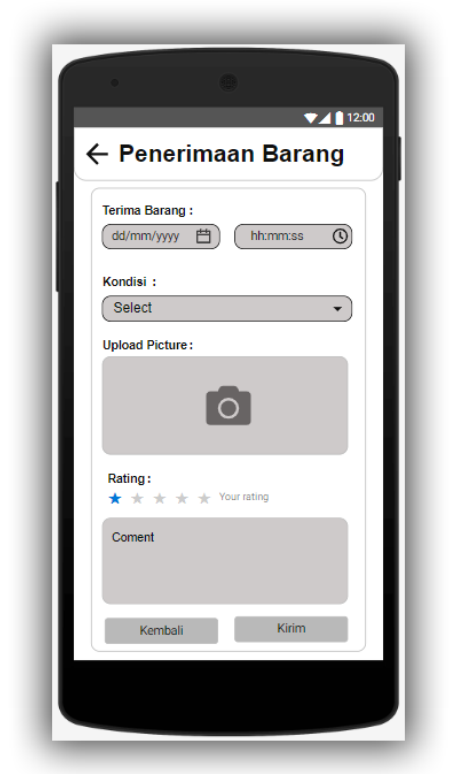

Gbr. 16 Rancangan Design Menu Penerimaan Barang

\section{Rancangan Arsitektur Sistem Informasi}

Pada gambar di bawah ini adalah arsitektur sistem informasi untuk usulan rencana pengembangan sistem e-SCM yang sudah dikembangkan sebelumnya untuk memudahkan proses pengiriman produk dengan adanya delivery order application berbasis mobile application dengan menggunakan dukungan jaringan internet.

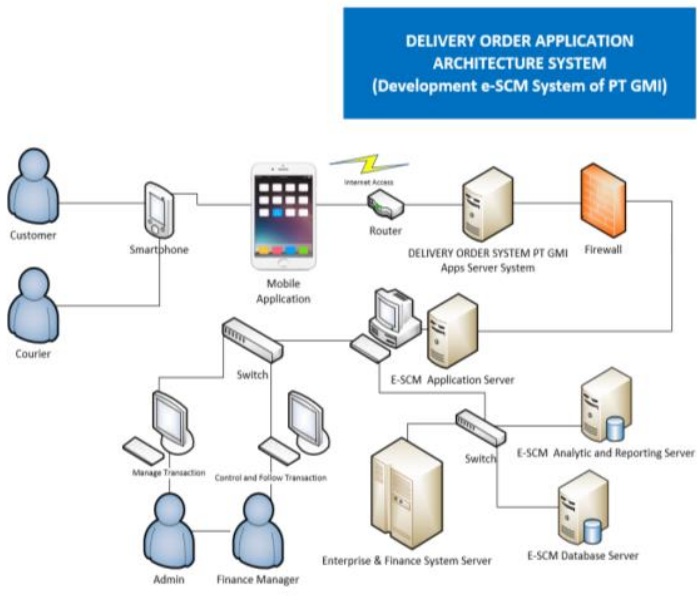

Gbr. 17 Rancangan Arsitektur Sistem Informasi Untuk Pengembangan Delivery Order Application System pada PT GMI

\section{J. Usulan Rencana Strategis Perusahaan}

Berdasarkan hasil analisa dalam penerapan konsep business process reengineering pada pengelolaan distribusi produk lensa mata di PT GMI maka ada beberapa rencana strategis yang perlu diusulkan bagi perusahaan yaitu sebagai berikut :

1. Aspek Key Partner : Meningkatkan hubungan dan komunikasi yang intensif dengan semua mitra kerja perusahaan. Perlunya menerapkan complaint management yang terukur serta evaluasi key performance indicator dari pencapaian service level agreement dari semua mitra yang terlibat, misalnya produsen terkait ketersediaan produk dan pelanggan terkait dengan ketepatan waktu pembayaran produk yang sudah dipesan.

2. Aspek Key Activities : Selalu memprioritaskan aspek-aspek kritis yang mendukung titik keberhasilan perusahaan dalam mencapai target bisnis. Aktifitas utama dari bisnis perusahaan harus selalu diupayakan dapat terselenggara dengan sebaik mungkin dengan dukungan faktor internal dan eksternal perusahaan yang memadai dan mendukung perusahaan dapat berkompetisi bisnis dengan optimal dalam proses distribusi produk lensa mata khususnya di Wilayah Indonesia.

3. Aspek Key Resources : Optimalkan seluruh sumber daya yang ada dalam perusahaan dengan efektif dan efisien. Selalu lakukan evaluasi atas kinerja karyawan serta sarana dan prasarana yang mendukung aktifitas kerja di perusahaan. Berlakukan standart operational procedure yang tepat dalam memanfaatkan sumber daya dalam perusahaan.

4. Aspek Value Propositions : Dalam mencapai nilai-nilai tujuan yang diharapkan perusahaan tercapai, harus melibatkan segenap komponen yang ada di internal dan eksternal perusahaan. Selain itu perusahaan juga harus fokus pada pencapaian visi perusahaan dengan mengatur misi-misi strategis dalam aktifitas berkesinambungan yang terukur dan senantiasa melakukan evaluasi pencapaian serta segera menyelesaikan hambatan-hambatan perusahaan dalam mencapai value propositions yang baik.

5. Aspek Customer Relationship : Membangun komunikasi yang efektif adalah salah satu kunci dalam menjaga hubungan relasi yang baik dengan pelanggan. Salah satu strategi yang dapat dioptimalkan adalah bagaimana saat ini pelanggan dapat lebih meningkatkan kepuasan pelanggan dengan menyediakan pengembangan sistem informasi yang tepat untuk memudahkan pelanggan juga dalam memantau proses pengiriman produk dari mitra kurir yang digunakan sampai dengan produk diterima, sehingga service level agreement dalam pengantaran produk dapat memenuhi target yang diharapkan oleh perusahaan.

6. Aspek Channels : Menjalin hubungan kerja sama yang baik dengan semua channels yang menjadi mitra kerja perusahaan. Selain itu selalu komitmen terhadap pemenuhan hak dan kewajiban dari kerja sama dengan channels dan memastikan aspek legalitas dari hubungan kerja sama dengan setiap mitra sesuai dengan ketentuan hukum yang berlaku dan dapat dipenuhi dengan baik oleh kedua belah pihak. Evaluasi secara 
berkala hubungan dengan mitra dan senantiasa melakukan perubahan serta perbaikan kedua belah pihak, sehingga tercipta hubungan kerja sama jangka panjang yang baik.

7. Aspek Customer Segments : Sebaiknya PT GMI melakukan diferensiasi produk dan harga dari kelompok segmentasi pelanggan yang memiliki perbedaan dalam hal diagnosa penyakit mata, kemampuan finansial, usia serta kebutuhan jaminan kesehatan jangka panjang setelah selesai operasi untuk memastikan produk berjalan sesuai fungsinya. Selain itu pastikan pelanggan dengan pembiayaan asuransi mendapatkan kualitas produk dan layanan yang sama baiknya dengan pelanggan yang tidak menggunakan asuransi agar kepuasan pelanggan tercapai disegala segmentasi pasar.

8. Aspek Cost Structure : Terutama bagian keuangan perusahaan harus melakukan evaluasi atas beban keuangan operasional yang dikeluarkan oleh perusahaan. Memastikan bahwa setiap biaya yang dikeluarkan dapat memaksimalkan operasional dengan efektif dan efisien sehingga pengembalian nilai terhadap perusahaan dapat tercapai tingkat profit yang baik dari masa ke masa. Selain itu perlu adanya tindakan-tindakan selektif dalam hal evaluasi pengajuan anggaran perusahaan dan pengeluaran perusahaan agar tepat guna mendukung tercapainya visi dan misi perusahaan.

9. Aspek Revenue Streams : Dalam upaya meningkatkan nilai pendapatan perusahaan, maka perlu dievaluasi dari segala aspek yang melibatkan hubungan internal dan eksternal perusahaan. Selain itu penting sekali memperhatikan strategi pemasaran yang diterapkan oleh kompetitor, jika ingin mengendalikan dan menguasai pasar maka sebaiknya menciptakan strategi, inovasi serta layanan pelanggan yang handal sehingga kinerja perusahaan dianggap baik dan dicapai customer loyalty yang optimal. Dampak dari customer loyalty yang optimal dapat meningkatkan revenue terhadap perusahaan dalam hal profit dan pengembangan bisnis jangka panjang.

\section{PENUTUP}

Berdasarkan hasil penelitian ini dapat disimpulkan beberapa hal yaitu :

a. Implementasi metode analisa value chain dan critical success factor dapat membantu perusahaan melakukan evaluasi mengenai kondisi perusahaan saat ini, nilai dan titik kritis perusahaan yang perlu dioptimalkan untuk mencapai strategi perusahaan yang tepat dalam meningkatkan nilai dan keuntungan perusahaan.

b. Proses Business Process Reengineering di PT GMI, setelah adanya pengukuran dari hasil analisa value chain dan critical success factor adalah dengan melakukan perubahan model bisnis yang tepat dengan memperhatikan dari aspek-aspek berikut : 1 . Customer Segment, 2. Value Proposition, 3. Channel, 4. Customer Relationship, 5. Revenue Stream, 6. Key Partner, 7. Key Activities, 8. Key Resource dan 9. Cost Structure untuk mendapatkan strategi perusahaan yang tepat untuk memperbaiki bisnis proses dan meningkatkan nilai serta keuntungan perusahaan.

c. Rancangan design sistem distribusi produk berbasis mobile application mengutamakan keterlibatan pelanggan dalam evaluasi kinerja kurir. Serta memastikan komunikasi dan pengawasan dengan kurir yang bertugas dalam pengiriman produk dapat dilakukan dengan mudah melalui aplikasi di smartphone dan perubahan data serta informasi dapat dilakukan secara real time dan up to date, sehingga dapat meningkatkan pelayanan PT GMI kepada seluruh pelanggannya.

Untuk penelitian lanjutan sebaiknya dilakukan perancangan dan implementasi sistem informasi sesuai dengan rekomendasi perubahan model bisnis dalam proses distribusi produk lensa mata yang dilakukan oleh PT GMI kepada para pelanggan. Selain itu perlu dilakukan evaluasi terhadap tingkat kepuasan pelanggan dan mitra dari efektifitas penerapan sistem informasi baru apakah sesuai dengan target yang diharapkan oleh perusahaan, dimana pemanfaatan teknologi diharapkan dapat membantu perusahaan meningkatkan nilai bisnis dan keuntungan perusahaan.

\section{UCAPAN TERIMA KASIH}

Terima kasih peneliti ucapkan kepada PT Galeri Mata Indonesia yang telah bersedia sebagai objek riset dalam penelitian ini. Selain itu kami ucapkan terima kasih kepada Universitas Mercu Buana, khususnya Lembaga Pusat Penelitian UMB yang sudah membantu sarana, prasarana serta pendanaan dalam proses penelitian yang dilakukan. Serta tidak lupa pula kami mengucapkan terima kasih kepada redaktur dan editor Journal of Computer Engineering, System and Science (Journal CESS) yang sudah membantu untuk mereview dan mempublikasikan hasil penelitian yang telah kami lakukan, agar dapat dipelajari dan dimanfaatkan oleh banyak pihak dalam pengayaan ilmu pengetahuan di bidang pengembangan sistem informasi, khususnya implementasi business process reengineering dalam suatu perusahaan.

\section{REFERENSI}

[1] Fitzgerald, Brian and Klass-Jan Stol. (2015). "Continuous Software Engineering : A Roadmap and Agenda”. Elsevier : The Journal of Systems and Sofware. DOI : https://doi.org/10.1016/j.jss.2015.06.063

[2] Deriani, Ni Wayan. (2017). "Pemilihan Konsep E-Commerce dan Business Process Re-engineering Penjualan Produk Olahan Kopi”. Konferensi Nasional Sistem \& Informatika 2017, STMIK STIKOM Bali, 10 Agustus 2017.

[3] Harahap, Ali Hasian. (2018). "Optimalisasi Proses Pengadaan Dengan Metode Rekayasa Ulang Bisnis Proses (BPR) Studi Kasus PT Inalum (Persero)". Universitas Sumatera Utara. 
[4] Porter, M.E. (1985). "Competitive Advantage : Creating and Sustaining Superior Performance”. New York : Simon and Schuster.

[5] Z. Alreemy, V. Chang, R. Walters, and G.Wills, "Critical Success Factors (CSFs) for information technology governance (ITG),” Int. J.Inf.Manage., vol.36, no.6, pp. 907916, 2016

Page | 12 [6] Edwita, Annisa, Sensuse, D.Indra, dan Noprisson, Handrie. (2017). "Critical Success Factors of Information System Development Projects". 2017 International Conference on Information Technology Systems and Innovation (ICITSI), Bandung, October 23-24, 2017. ISBN : 978-1-5386-3100-3.

[7] Wisayani, Ni Luh, Kertahadi, dan Riyadi. (2014). "Analisis Business Process Reengineering Untuk Mengevaluasi, Merekayasa Ulang, dan Memperbaiki Monitoring Kontrak Pada PT PLN (Persero) Dist. Jatim Area Malang”. Jurnal Administrasi Bisnis (JAB), Vol.8 No.1 Februari 2014. https://administrasibisnis.studentjournal.ub.ac.id

[8] Wimpertiwi, Dotty, Agung H. Sasongko, dan Antonius Kurniawan. (2014). "Konsep Business Process Reengineering Untuk Memperbaiki Kinerja Bisnis Menjadi Lebih Baik : Studi Kasus Perusahaan Susu Kedelai "XYZ". Binus Business Review, Vol.5 No.2 November 2014; 658668.

[9] Wiyono, Dani Eko, Farhan HM.S, dan Taufiq Immawan. (2016). "Konsep Business Process Engineering Guna Pembenahan Sistem dan Kinerja Bisnis Perusahaan Manufaktur". Teknoin Vo. 22 No. 3 September 2016 : 01-08.

[10] Esbenshade, Jill, et.al. (2016). "Customer-driven Management Models for Choiceless Clientele? Business Process Reengineering in California Welfare Agency". Sagepub.co.uk/journalsPermissions.nav. DOI 10.1177/0950017015604109

[11] Devianto, Yudo \& Dwiasnati, Saruni,. (2018). “Application of e-Business on The Application of Corporate Social Responsibility (CSR) Data Processing”. International Journal of Computer Techniques-Volume 5, Issue 4 July-Aug 2018. Page 37-44. ISSN : 2394-2231.

[12] R.Sahara, \& I.Ranggadara. (2018). "Design and Implementation of Treasury Application Based on Mobile in Student Organization Mercu Buana University". International Journal of Computer Science and Mobile Computing, Vol.7,Issue.2, February 2018,pg.1-8.ISSN 2320-088X.

[13] Hayati, Nur. (2016). "Analisis Bisnis Internal dengan Metode Critical Success Factors (CSF) dan Value Chain (Studi Kasus PT. Farmasi X)". Jurnal Ilmiah FIFO. Volume VIII/No.1/Mei/2016. Hal.62-71. P-ISSN 2085-4315 / E-ISSN 2502-8332.

[14] Osterwalder, A., and Pigneur, Y. (2012). "Business Model Generation". Jakarta : Elex Media Komputindo.

[15] Sari, Yunita Sari. (2018). “Analysis and Design Outpatient Administration Information System With Object Oriented Methodology". International Educational Journal of Science and Engineering. Volume : 1, Issue : 4, November 2018. EISSN No. 2581-6195. 